\title{
Rehabilitation Protocols for Superior Capsular Reconstruction Are Variable: A Systematic Review
}

\author{
Alessia C. Lavin, B.S., Kailey L. Mansour, B.S., Dylan N. Greif, B.A., \\ Brandon J. Shallop, M.D., Paul R. Allegra, M.D., Rafael A. Sanchez, M.D., \\ Julianne Muñoz, M.D., and Michael G. Baraga, M.D.
}

\begin{abstract}
Purpose: To screen manuscripts that discuss rehabilitation protocols for patients who underwent superior capsular reconstruction (SCR) to elucidate whether a standard rehabilitation algorithm exists for SCR. Methods: A systematic review was conducted according to the Preferred Reporting Items for Systematic Reviews and Meta Analyses (i.e., PRISMA) guidelines. PubMed (MEDLINE) and Embase were searched using pertinent Boolean operation terms "superior capsular reconstruction" and "rotator cuff repair rehabilitation," and articles that included rehabilitation protocols following superior capsular reconstruction surgery were reviewed. Two independent reviewers performed the search and quality assessment. Results: A total of 549 articles were yielded after our database search. Fourteen studies fulfilled our inclusion criteria and were included in the review. Study designs included 9 editorials, 3 case series, and 2 case reports. Each study included in this review used a unique rehabilitation algorithm that posed significant variability between the protocols. Four phases were identified to summarize each protocol and were used as a basis of discussion-sling versus brace time (3-6 weeks for comfort/removal vs complete immobilization), passive range of motion (immediately after surgery to initiation at 6 weeks), active range of motion (4-8 weeks), and strengthening/return to full activity (12-52 weeks). Initiation of rehabilitation, length of time spent in each phase, types of exercises, and overarching goals for return to function were significantly variable and were decided upon by the surgeon based on current massive rotator cuff repair protocols. Presently, there is no standard rehabilitation protocol for SCR. Conclusions: SCR is a relatively new procedure that is gaining rapid popularity with promising outcomes. Based on our review, there is no standard rehabilitation protocol in place; thus, it is not possible to recommend an evidence-based rehabilitation protocol following SCR at this time. Level of Evidence: Level V, systematic review of Level IV and V studies.
\end{abstract}

A subset of rotator cuff tears (RCTs) are considered irreparable due to poor tissue quality, prolonged fixed retraction, or size (tears greater than $5 \mathrm{~cm}$ ). ${ }^{1}$ However, patients with irreparable tears in the absence of shoulder arthritis may be amenable to surgical intervention aimed at joint preservation. ${ }^{2}$ Historically, there have been high failure rates associated with surgical repair. ${ }^{3}$ Several alternative treatments have

From the University of Miami Sports Medicine Institute, Coral Gables, Florida, U.S.A.

The authors report that they have no conflicts of interest in the authorship and publication of this article. Full ICMJE author disclosure forms are available for this article online, as supplementary material.

Received June 25, 2020; accepted January 3, 2021.

Address correspondence to Alessia C. Lavin, B.S., 5555 Ponce de Leon Blvd., 3rd Floor, Coral Gables,FL 33146. E-mail: a.lavin1@med.miami.edu

(C) 2021 THE AUTHORS. Published by Elsevier Inc. on behalf of the Arthroscopy Association of North America. This is an open access article under the CC BY-NC-ND license (http://creativecommons.org/licenses/by-nc-nd/4.0/). 2666-061X/20985

https://doi.org/10.1016/j.asmr.2021.01.001 been tested, such as partial repairs, patch autograft or allograft application, and latissimus dorsi tendon transfers. ${ }^{4}$ However, these procedures have yielded mixed results with a high risk of complications.

In response, superior capsular reconstruction (SCR) ${ }^{5}$ has been recommended as a joint-sparing treatment for irreparable RCTs. ${ }^{6}$ SCR prevents translation of the humeral head and improves biomechanical stability and force coupling of the remaining cuff. ${ }^{1}$ Although the procedure is fairly novel, multiple studies have demonstrated positive outcomes despite differences in surgical nuances. ${ }^{1,4,6-10}$

The postoperative rehabilitation protocol is an important component for a successful result. For SCR, although there is literature discussing the different variations of the procedure, there is no literature comparing postoperative rehabilitation protocols. Currently there are therapy guidelines suggested by various surgeons relatively experienced in SCR. ${ }^{11}$ Therefore, the purpose of this systematic review is to screen manuscripts that discuss rehabilitation protocols 

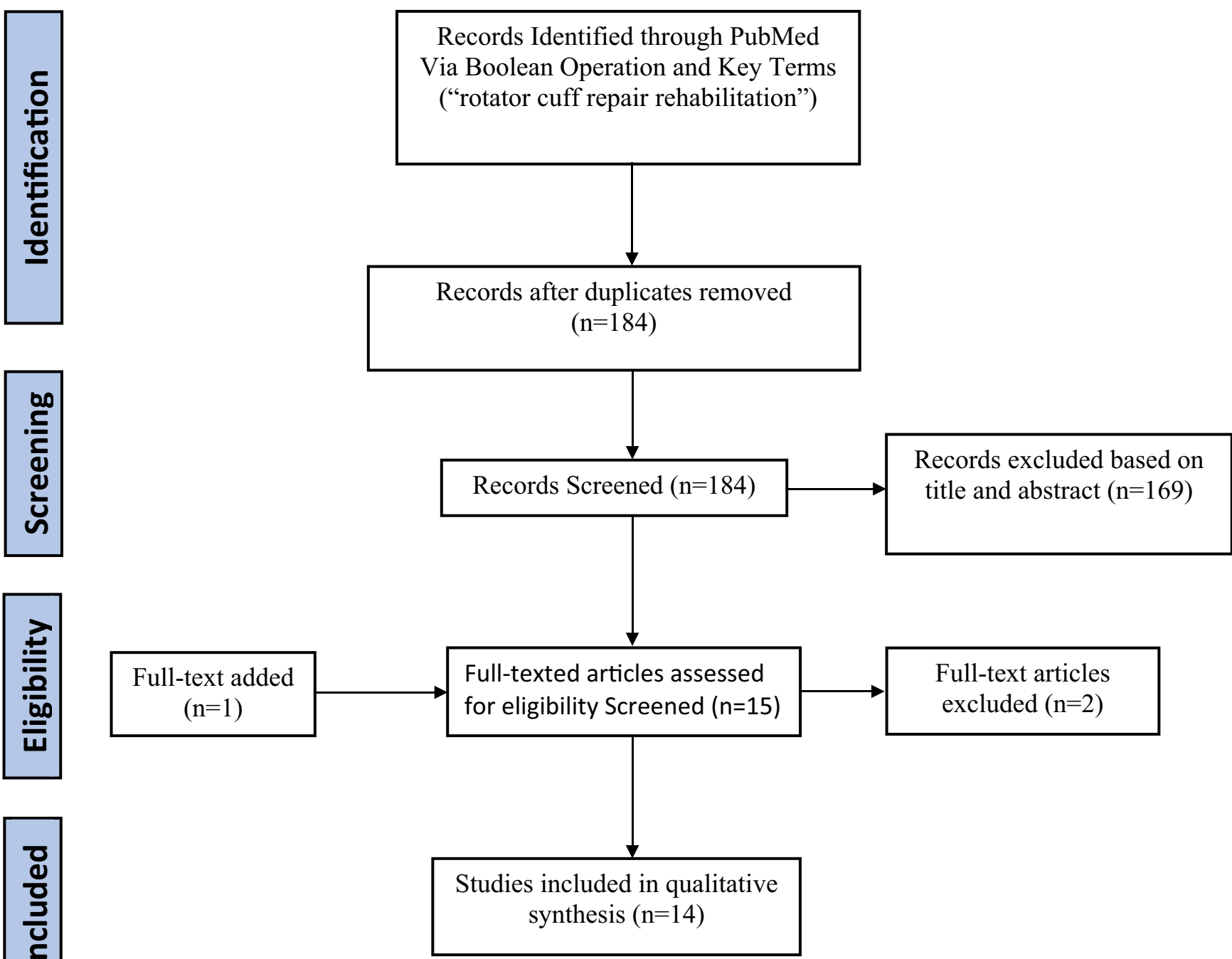

Fig 1. PRISMA flow chart.

for patients who underwent SCR to elucidate whether a standard rehabilitation algorithm exists for SCR. We hypothesized that there would be significant variability of published protocols, confirming that there is no standard rehabilitation protocol in place.

\section{Methods}

A systematic review was conducted according to Preferred Reporting Items for Systematic Reviews and Meta Analyses (i.e., PRISMA) guidelines to identify all studies that included rehabilitation protocols following SCR (Fig 1). Two reviewers (A.L., K.M.) independently conducted literature searches in September of 2019 using PubMed (MEDLINE) and Embase database. The search included the following terms: "rotator cuff repair rehabilitation" and "rotator cuff repair rehabilitation."

The main criteria for selection were articles within the aforementioned database that were written in English, published within the last 10 years, and described a rehabilitation protocol for SCR. In addition, selected studies had to include the following parameters: massive rotator cuff injury, completion of defined rehabilitation program, and patient age of 18 years or older. Review articles and meta-analyses were excluded, as we focused on reported cases or clinical studies that employed a specific rehabilitation protocol. Both reviewers independently filtered through all returned articles based on the title and abstract, identified appropriate articles, and any subsequent discrepancies were co-reviewed. Articles were then screened by the senior authors for final inclusion.

Two reviewers then assessed the quality of each of the included articles using the Case Report (CARE) guidelines. ${ }^{12}$ The assessment was carried out independently by 2 reviewers addressing the 30 items reported by the guidelines. Possible item ratings are yes or no; any disagreement was discussed among the reviewers and 
Table 1. Study Characteristics

\begin{tabular}{|c|c|c|c|c|c|c|c|}
\hline Study & Year & Study Type & Sling & Passive ROM & Active ROM & Strengthening & Full Activity \\
\hline Anderson and Trenhaile $^{6}$ & 2018 & Editorial & $\begin{array}{l}\text { Abduction sling at all times } \\
\text { for first } 4 \text { weeks }\end{array}$ & First 4 weeks as tolerated & $\begin{array}{l}\text { Start gentle passive } \\
\text { stretching at } 4 \\
\text { weeks and active ROM } \\
\text { at } 6 \text { weeks }\end{array}$ & 8 weeks & Not specified \\
\hline Cabarcas et al. $^{1}$ & 2018 & Editorial & $\begin{array}{l}\text { Sling with abduction pillow } \\
\text { for } 6 \text { weeks; Only ROM } \\
\text { at the elbow, wrist, and } \\
\text { hand is allowed }\end{array}$ & $\begin{array}{l}\text { 6-8 weeks, patients are } \\
\text { allowed passive ROM } \\
\text { and grip-strengthening } \\
\text { exercises; ROM goals are } \\
140^{\circ} \text { of forward } \\
\text { elevation, } 40^{\circ} \text { of external } \\
\text { rotation at the side, and } \\
\text { maximum } 60^{\circ} \text { to } 80^{\circ} \text { of } \\
\text { abduction }\end{array}$ & $\begin{array}{l}\text { Active assisted ROM at } \\
\text { weeks } 8-12 \text { (ROM goals } \\
\text { are the same as in weeks } \\
6 \text { to } 8 \text {, but with the } \\
\text { incorporation of light } \\
\text { passive stretches at end } \\
\text { ranges); from months } 3 \\
\text { to } 12 \text {, patients are } \\
\text { advanced to full ROM } \\
\text { with passive stretching at } \\
\text { end ranges }\end{array}$ & $\begin{array}{l}\text { Isometric strengthening } \\
\text { exercises permitted at } \\
\text { weeks } 8 \text {-12; } \\
\text { Eccentrically resisted } \\
\text { exercises, plyometrics, } \\
\text { and proprioception } \\
\text { routines are started after } \\
\text { week 16; from months } 3 \\
\text { to } 12 \text {, advanced } \\
\text { strengthening exercises } \\
3 \text { times per week, } \\
\text { including isometrics, } \\
\text { resistance bands, and } \\
\text { light weights (1-5 lb) }\end{array}$ & $\begin{array}{l}\text { Should have full recovery } \\
\text { by } 12 \text { months }\end{array}$ \\
\hline $\begin{array}{l}\text { de Campos } \\
\text { Azevedo et al. }{ }^{3}\end{array}$ & 2018 & Case series & $\begin{array}{l}\text { Wear sling for } 3 \text { weeks, but } \\
\text { remove it several times a } \\
\text { day to perform active } \\
\text { assisted shoulder } \\
\text { elevation and elbow } \\
\text { flexion exercises }\end{array}$ & & & $\begin{array}{l}\text { No active resistant elbow } \\
\text { exercises until } 6 \text { weeks } \\
\text { postoperatively; active } \\
\text { shoulder resistant } \\
\text { exercises not allowed } \\
\text { until } 6 \text { months } \\
\text { postoperatively }\end{array}$ & $\begin{array}{l}\text { Return to full activity } \\
\text { allowed at } 6 \text { months }\end{array}$ \\
\hline Boutsiadis et al. ${ }^{4}$ & 2017 & editorial & $\begin{array}{l}\text { Abduction pillow at } 60 \\
\text { degrees for } 6 \text { weeks; } \\
\text { active hand, wrist, and } \\
\text { elbow exercises are } \\
\text { allowed from the first } \\
\text { day }\end{array}$ & 15 days postoperatively & 6 weeks & $\begin{array}{l}\text { No strengthening or } \\
\text { resistance exercises } \\
\text { before } 6 \text { months }\end{array}$ & $\begin{array}{l}\text { Start working on } \\
\text { performing daily } \\
\text { activities at } 6 \text { weeks }\end{array}$ \\
\hline Mihata et al. ${ }^{13}$ & 2013 & Case series & $\begin{array}{l}\text { Abduction pillow for } 4 \\
\text { weeks with complete } \\
\text { immobilization }\end{array}$ & $\begin{array}{l}\text { Passive and active-assisted } \\
\text { exercises initiated after } 4 \\
\text { weeks }\end{array}$ & $\begin{array}{l}\text { Passive and active-assisted } \\
\text { exercises initiated after } 4 \\
\text { weeks }\end{array}$ & $\begin{array}{l}\text { After } 8 \text { weeks, start } \\
\text { exercises to strengthen } \\
\text { rotator cuff and scapula } \\
\text { stabilizers }\end{array}$ & \\
\hline Chillemi et al. ${ }^{2}$ & 2018 & Editorial & $\begin{array}{l}\text { Abduction pillow at } 20^{\circ} \text { for } \\
30 \text { days }\end{array}$ & $\begin{array}{l}\text { Passive shoulder } \\
\text { mobilization and active } \\
\text { hand, wrist, and elbow } \\
\text { exercises started from } \\
\text { the first day after surgery }\end{array}$ & $\begin{array}{l}\text { Active-assisted shoulder } \\
\text { exercises were allowed } \\
\text { from the first month } \\
\text { postoperatively }\end{array}$ & $\begin{array}{l}\text { From month } 2 \text {, } \\
\text { strengthening exercises } \\
\text { of the deltoid were } \\
\text { allowed }\end{array}$ & \\
\hline
\end{tabular}




\begin{tabular}{|c|c|c|c|c|c|c|c|}
\hline Study & Year & Study Type & Sling & Passive ROM & Active ROM & Strengthening & Full Activity \\
\hline Frank et al. $^{8}$ & 2018 & Editorial & $\begin{array}{l}\text { Abduction sling for } 6 \\
\text { weeks, with pendulum } \\
\text { exercises and elbow and } \\
\text { wrist ROM permitted. }\end{array}$ & & $\begin{array}{l}\text { At week 6, active-assist } \\
\text { ROM is permitted, } \\
\text { progressing to active } \\
\text { ROM }\end{array}$ & $\begin{array}{l}\text { Scapular exercises allowed } \\
\text { at week 6. Gentle } \\
\text { isometric exercises with } \\
\text { arm at side are allowed } \\
\text { at week } 8 \text {. Formal } \\
\text { strengthening initiated at } \\
3 \text { months }\end{array}$ & $\begin{array}{l}\text { Sport-specific } \\
\text { rehabilitation started no } \\
\text { earlier than 4-5 months }\end{array}$ \\
\hline Pennington et al. ${ }^{9}$ & 2018 & Case series & For comfort & $\begin{array}{l}\text { Allowed during the first } 4 \\
\text { weeks }\end{array}$ & $\begin{array}{l}\text { Active assisted motion } \\
\text { begins at } 4 \text { weeks and } \\
\text { full active motion begins } \\
\text { at } 8 \text { weeks }\end{array}$ & & \\
\hline Tajika et al. ${ }^{10}$ & 2018 & Case report & $\begin{array}{l}\text { Abduction brace for } 3 \\
\text { weeks, then sling for } 2 \\
\text { weeks after }\end{array}$ & Day after surgery & $\begin{array}{l}\text { Unrestricted active ROM } \\
\text { started } 5 \text { weeks } \\
\text { postoperatively }\end{array}$ & & \\
\hline Kim et al. ${ }^{14}$ & 2018 & Editorial & $\begin{array}{l}\text { Abduction brace for } 4-6 \\
\text { weeks. NO passive } \\
\text { motion of the elbow } \\
\text { allowed while wearing } \\
\text { brace }\end{array}$ & $\begin{array}{l}\text { Start passive ROM at } 4-6 \\
\text { weeks after removal of } \\
\text { brace }\end{array}$ & $\begin{array}{l}\text { Active ROM starts after } 8 \\
\text { weeks }\end{array}$ & $\begin{array}{l}\text { External rotation } \\
\text { strengthening starts at } 12 \\
\text { weeks }\end{array}$ & \\
\hline Laskovski et al. ${ }^{15}$ & 2018 & Editorial & $\begin{array}{l}\text { Placed with abduction } \\
\text { pillow for } 6 \text { weeks }\end{array}$ & Allowed at 6 weeks & Allowed at 12 weeks & & \\
\hline Pennington et al. ${ }^{16}$ & 2018 & Editorial & For comfort & $\begin{array}{l}\text { Allowed during the first } 4 \\
\text { weeks }\end{array}$ & $\begin{array}{l}\text { Active assisted motion } \\
\text { begins at } 4 \text { weeks and } \\
\text { full active motion begins } \\
\text { at } 8 \text { weeks }\end{array}$ & & \\
\hline Tokish et al. ${ }^{17}$ & 2018 & Case report & $\begin{array}{l}\text { Shoulder immobilizer with } \\
\text { an abduction pillow is } \\
\text { used, and the patient is } \\
\text { encouraged to perform } \\
\text { elbow, wrist, and hand } \\
\text { exercises for } 6 \text { weeks, } \\
\text { along with gentle passive } \\
\text { glenohumeral motion }\end{array}$ & $\begin{array}{l}\text { Gentle passive } \\
\text { glenohumeral motion } \\
\text { for first } 6 \text { weeks }\end{array}$ & $\begin{array}{l}\text { Progressive motion started } \\
\text { at } 6 \text { weeks }\end{array}$ & Beginning at 12 weeks & $\begin{array}{l}\text { Gradually returned to } \\
\text { activity when motion, } \\
\text { strength, and confidence } \\
\text { return over a 6- month } \\
\text { period }\end{array}$ \\
\hline Petri et al. ${ }^{18}$ & 2015 & Editorial & Abduction sling & $\begin{array}{l}\text { Focused on limited and } \\
\text { protected passive ROM } \\
\text { postsurgery }\end{array}$ & $\begin{array}{l}\text { Both active and active } \\
\text { assisted ROM begin at } 6 \\
\text { weeks }\end{array}$ & Begins at 8 weeks & \\
\hline
\end{tabular}


ultimately mediated by a third reviewer. Inter-rater reliability of scoring during the assessment was tested.

For the purposes of this review, we chose 4 phases that are widely accepted in orthopaedic rehabilitation practice to make comparisons between each article: sling time, passive range of motion (ROM), active ROM, and strengthening/return to full activity.

\section{Results}

Dual review of current, relevant literature resulted in a total of 549 articles for review. Both reviewers finalized a list of 13 articles based on title and abstract for further full-text screening. One article was excluded due to it being a systematic review. One additional article that was found on review of citations was added. A total of 14 articles published from 2017 to 2019 were finally included in this review, with detailed descriptions provided in Table 1. - $^{-4,6,8-10,13-18}$

A variety of study designs were included as follows: 9 editorials, 3 case series, and 2 case reports. All articles were assigned as Level VI evidence. The quality of each article was evaluated by 2 independent reviewers using the CARE guidelines. The CARE score was calculated by summing the number of "yes" response to each item. On average, the articles yielded a score of 26.4 of 30 . The intraclass correlation coefficient for the inter-raters CARE score was excellent $(0.967 ; 95 \%$ confidence interval 0.90-0.99; $P<.001$ ).

The length of time and goals for return to function was decided by the surgeon and was not based on a defined standard specific for SCR. Thus, each study included in this review employed a different rehabilitation algorithm with considerable variability between their protocols, ranging from time spent in immobilization after surgery to return to activity. In addition, 5 articles used a variation of an established protocol for massive rotator cuff repair. ${ }^{1,4,7,8,16}$

\section{Phase One: Sling Time}

The first phase assessed was the time spent in a sling or abduction brace with the goal of protecting the surgical repair immediately after surgery by providing support for the glenohumeral joint. ${ }^{19}$ Overall, a sling or brace was generally employed for 4 to 6 weeks. Chillemi et al. ${ }^{2}$ advocated for sling use for a strict time period of only 30 days. A noteable outlier was de Campos Azevedo et al., ${ }^{3}$ who demonstrated the use of an aduction brace for 3 weeks with removal several times per day, followed by a sling for 2 weeks. Eleven studies specified lengths of time that patients were required to wear either device, and 3 did not. ${ }^{1-4,6,8-10,13-18}$ Two papers, Kim et al. ${ }^{14}$ and Laskovski et al., ${ }^{15}$ stressed the importance of wearing the sling for 6 weeks with no motion of the shoulder.

The other 11 studies advocated for the removal of the sling periodically to perform minimal exercises. Among the articles that called for exercise during this phase, 4 articles allowed for exercises involving only the hand, wrist, and elbow to maintain accessory joint mobility. ${ }^{1,4,10,20}$ Alternatively, 8 studies initiated passive ROM of the shoulder immediately after surgery while the patient was still using the sling. ${ }^{2,3,6,8-10,16,17}$ de Campos Azevedo et al. $^{3}$ was the only study to advocate for active assisted shoulder motion immediately after surgery, although their rationale for such early active mobilization was not provided.

\section{Phase Two: Passive ROM}

We subsequently compared the time of initiation of passive ROM exercises. Ten studies advocated for the immediate implementation of passive ROM exercises after surgery. ${ }^{2-4,6,8-10,16-18}$ The other 4 studies emphasized waiting 2 to 8 weeks after surgery or after sling/ brace removal. ${ }^{1,13-15}$ Boutsiadis et al. $^{4}$ were the only authors to specify a precise time point of 15 days after surgery in order to start any passive ROM of shoulder. Two articles mentioned implementation of passive ROM 6-8 weeks postoperatively to allow early time for the dermal allograft and rotator cuff healing. ${ }^{1,15}$ Interestingly, Cabarcas et al. ${ }^{1}$ was the only paper to define their passive ROM goals, which were $140^{\circ}$ of forward flexion, $40^{\circ}$ of external rotation at the side, and maximum 60 to $80^{\circ}$ abduction.

\section{Phase Three: Active ROM}

Again, there was significant variation among all studies. Of the 14 studies in this review, 11 studies implemented active ROM sooner postoperatively. ${ }^{2-4,6,8-10,13,16-18}$ Chillemi et al. $^{2}$ describes the earliest implementation; active-assisted shoulder exercises after the first month postoperatively. In both of their papers, Pennington et al. ${ }^{9,16}$ encouraged the initiation of active assisted motion at 4 weeks and full active motion at 8 weeks. Mihata et al. ${ }^{13}$ started both passive and active-assisted exercises in week 5, with the goal of promoting scapular plane elevation. Tajika et al. ${ }^{10}$ supported initiation of unrestricted active ROM 5 weeks after surgery.

Three papers waited 8-12 weeks or longer to start active ROM. ${ }^{1,14,15}$ Cabarcas et al. ${ }^{1}$ advocated for active assisted ROM to begin at 8 to 12 weeks, with advancement to full ROM from months 3 to 12 . Once again, this was the only paper to set specific goals for this phase of rehabilitation; the ROM goals were the same as in the passive ROM stage, but with incorporation of light passive stretches at end ranges to increase flexibility. ${ }^{1,21}$ Kim et al. ${ }^{14}$ began active ROS at eight weeks and Laskovski et al. ${ }^{15}$ started at 12 weeks with explanation of their rationale.

\section{Phase Four: Strengthening/Return to Activity}

Again, we found that the majority of articles did not provide any specifics for this phase beyond basic 
timelines. In 8 of 14 studies, a more aggressive approach was employed, calling for strengthening to begin as early as 6 to 12 weeks postoperatively. Only Cabarcas et al. ${ }^{1}$ emphasized starting isometric strengthening exercises 8 to 12 weeks and eccentrically resisted exercises, plyometrics, and proprioception routines by week 16. From months 3 to 12, advanced strengthening needed to be completed 3 times per week and should incorporate isometrics, resistance bands, and light weights. Frank et al. ${ }^{8}$ discussed initiation of scapular exercises at week 6 , gentile isometric exercises with arm at side at week 8 , and formal strengthening at 3 months. Mihata et al. ${ }^{13}$ describes starting exercises to strengthen the rotator cuff and scapula stabilizers at 8 weeks. Kim et al. ${ }^{14}$ specified that strengthening should start at week 12 and be exclusive to external rotation exercises. Two articles recommended delaying strengthening until 6 months; 4 articles did not specify a time for the introduction of strengthening. $3,4,9,10,15,16$

There was no consensus regarding the definition of return to activity of when patients would be allowed to return. De Campos Azevedo et al. ${ }^{3}$ and Frank et al. ${ }^{8}$ described return to full activity to be expected at 6 months. In comparison, Cabarcas et al. ${ }^{1}$ cited that full activity by 12 months postoperatively is appropriate.

\section{Discussion}

SCR is a complicated surgery used to treat massive RCTs, yet despite the extensive rehabilitation necessary for this procedure, no formal postoperative rehabilitation protocol has been established. Among the articles reviewed here, there is substantial variation regarding the timeline and rate of progression for each phase of rehabilitation. However, there were common themes in each study, usually involving a short course of immobilization with progression to passive and active ROM, followed by strengthening exercises and ultimately return to unrestricted activity. Because we divided each protocol into 4 distinct phases, the protocols for each article in this review can be discussed further in context with one another.

The first phase saw quite a bit of variation, with some authors advocating for use of a sling for 30 days, ${ }^{2,13}$ whereas others opted wearing a sling for up to 6 weeks with no mobility allowed whatsover. ${ }^{14,15}$ In particular, Kim et al. ${ }^{14}$ reasoned that when the long head of the biceps is used for repair, it is important to avoid any passive ROM of the elbow and shoulder while wearing the sling. This stark contrast suggests some clinicians believe early removal of a sling or brace may prevent stiffness and allow for quicker restoration of ROM and return to activity, whereas others believe that preservation of the surgical repair is a priority over early mobilization, ${ }^{2,3,19,22}$ The reasoning behind early initiation of passive ROM can be linked to a study by Li et al., which showed that passive ROM after surgery promotes tendon-bone healing by increasing type 3 collagen production at the tendon-bone interface. ${ }^{23,24}$ Therefore, when to discontinue supportive devices as well as if initiation of passive ROM in phase 1 is appropriate remains undefined in patients undergoing SCR.

Furthermore, even when the SCR articles discuss passive ROM without the use of a supportive devices, there remains little clarity as to what joints should be involved. Three articles specified that the passive ROM should be limited to hand, wrist, and elbow, ${ }^{1,4,22}$ whereas one article limited passive ROM to elbow and wrist only. ${ }^{2}$ Only Tokish et al. ${ }^{17}$ included gentle passive ROM of the glenohumeral joint, which is significant because previous literature suggests passive ROM of the glenohumeral joint as soon as possible is necessary to minimize joint stiffness and postoperative morbidity. ${ }^{19}$ Due to the aforementioned, there is no consensus regarding initiation of passive ROM in isolation and if glenohumeral passive ROM can begin at the same time as accessory upper extremity joints.

The lack of consensus is also evident in phase 3 and 4 . For phase 3, whereas previous literature suggests strength and gradual introduction of resistance training is recommended to begin by 12 weeks for patients with massive rotator cuff, others mention that patients should have $50 \%$ of normal strength by 12 weeks and full strength by 15 weeks. ${ }^{25}$ There is no literature defining a range for strengthening in patients undergoing SCR. For the 5 articles claiming to use massive rotator cuff protocol, none reported when they initiated strength or resistance exercises. For articles defining their own protocols, phase 3 began from 6 weeks to 6 months. However, Chillemi et l. $^{2}$ were the only authors to mention that deltoid strengthening must begin by week 8 but did not provide any rationale. Greiner et al. ${ }^{26}$ demonstrated that atrophy of the deltoid after reverse shoulder arthroplasty negatively impacted clinical outcomes because the deltoid assumes the function of the rotator cuff during the acute phases of healing after SCR surgery. Therefore, early deltoid strengthening may be important for SCR patients and warrants further exploration.

The variation in return to full activity leads to the conclusion that there is no consensus between the standard protocols followed. Typically, patients who have high expectations of their return to activity will push their rehabilitation progression. ${ }^{27}$ In addition, the demographic cohorts for each article varied, which may alter what full activity meant for their respective patient populations. This can cause differences in rehabilitation expectations as well as variations in the type of rehabilitation endured.

Only 4 articles in this review highlighted the final outcomes of their patients, and only 2 articles touched on failure rates and complications encountered. Since 
only a handful of articles reported the outcomes of their patients, and one specifically addressed failure rates, there are potentially other unreported complications within this entire cohort reviewed. Furthermore, any reported outcome of these articles cannot be solely attributed to surgical techniques as there are many varying factors, specifically rehabilitation.

\section{Rehabilitation Protocol}

As there is no standardized rehabilitation protocol for SCR, the authors of this review opted to formulate our own protocol currently being used in all patients undergoing SCR at our institution. This protocol is categorized into 5 phases based on postoperative timing. Our protocol advocates for no active movement of the shoulder joint until 6 weeks postoperatively.

Phase one is defined as postoperative day 9 to 2 weeks. During this phase, the patient is instructed to use the sling continuously. Passive and active ROM of the elbow, wrist, and neck are initiated within $0-50^{\circ}$ as tolerated. All patients progress to phase 2 after postoperative day 14, which continues until 5 weeks postoperatively. The sling is slowly weaned off during weeks 5-6, and there is no active shoulder motion. The goals of phase 2 are to restore passive ROM, activate shoulder and scapular stabilizers in the protected position, and correct postural dysfunction.

Phase 3 begins between around 6 weeks postoperatively. Active abduction is not initiated during the first 8 weeks, and no resistance for abduction or supraspinatus strengthening for the first ten weeks. Progression to phase 4 is only allowed once the patient has achieved full active ROM and full strength for internal and external rotation at $30^{\circ}$ abduction.

Phase 4 should be initiated at 12 to 14 weeks postoperatively. The goal of this phase is to attain full rotator cuff strength and endurance at $90^{\circ}$ of abduction. Once these goals have been met and impingement signs are negative, the patient is cleared for phase 5 .

The objective of phase 5 is to attain full rotator cuff strength at $90^{\circ}$ abduction as well as to continue to develop strength and control for work and recreationspecific tasks. Once the physical therapist and surgeon have assessed the patient's ability to meet these goals, the patients are cleared for daily activities or return to recreational activity.

\section{Limitations}

This study has limitations, the first being the level of evidence and quality of available literature. The only studies that fit our inclusion criteria were editorials, case reports, and case series. For this reason, the authors could not perform an in-depth statistical analysis and were unable to directly compare outcomes associated with the different rehabilitation protocols. Multiple studies were excluded from this review due to the fact that they did not include a postoperative rehabilitation protocol despite evaluating SCR. Some articles were not written in English, which may have provided some guidance.

Another limitation of this review was the variability in the surgical technique and graft choice. As seen in Table 1, the studies in this review recommended different surgical techniques, such as long head of the biceps tendon transfer and supplemental partial rotator cuff repair. Studies also employed different types of grafts, including dermal acellular and fascia lata grafts.

\section{Conclusions}

SCR is a relatively new procedure that is gaining rapid popularity with promising outcomes. Based on our review, there is no standard rehabilitation protocol in place, thus it is not possible to recommend an evidencebased rehabilitation protocol following SCR at this time.

\section{References}

1. Cabarcas BC, Garcia GH, Gowd AK, Liu JN, Romeo AA. Arthroscopic superior capsular reconstruction and over-the-top rotator cuff repair incorporation for treatment of massive rotator cuff tears. Arthrosc Tech 2018;7:e829-e837.

2. Chillemi C, Mantovani M, Gigante A. Superior capsular reconstruction of the shoulder: The $\mathrm{ABC}$ (Arthroscopic Biceps Chillemi) technique. Eur J Orthop Surg Traumatol 2018;28:1215-1223.

3. de Campos Azevedo CI, Ângelo ACLPG, Vinga S. Arthroscopic superior capsular reconstruction with a minimally invasive harvested fascia lata autograft produces good clinical results. Orthop J Sports Med 2018;6: $2325967118808242-2325967118808242$.

4. Boutsiadis A, Chen S, Jiang C, Lenoir H, Delsol P, Barth J. Long head of the biceps as a suitable available local tissue autograft for superior capsular reconstruction: "The Chinese way." Arthrosc Tech 2017;6:e1559-e1566.

5. Ambrosino P, Scrutinio D, De Campi M, et al. Diffuse idiopathic skeletal hyperostosis in subjects with congestive heart failure undergoing cardiac rehabilitation: A decision tree analysis. J Rehabil Med 2020;52:jrm00030.

6. Anderson S, Trenhaile S. All knot-less arthroscopic superior capsular reconstruction. Arthrosc Tech 2018;7: e811-e816.

7. Cuff DJ, Pupello DR. Prospective randomized study of arthroscopic rotator cuff repair using an early versus delayed postoperative physical therapy protocol. J Shoulder Elbow Surg 2012;21:1450-1455.

8. Frank RM, Cvetanovich G, Savin D, Romeo AA. Superior capsular reconstruction: Indications, techniques, and clinical outcomes. JBJS Rev 2018;6:e10.

9. Pennington WT, Bartz BA, Pauli JM, Walker CE, Schmidt W. Arthroscopic superior capsular reconstruction with acellular dermal allograft for the treatment of massive irreparable rotator cuff tears: Short-term clinical outcomes and the radiographic parameter of superior capsular distance. Arthroscopy 2018;34:1764-1773. 
10. Tajika Y, Nishinaka N, Uehara T, Tsutsui H. Arthroscopic superior capsular reconstruction for dislocation of the shoulder with an irreparable rotator cuff tear: A case report. JBJS Case Connector 2018;8:e101.

11. Pogorzelski J, DelVecchio BM, Hussain ZB, Fritz EM, Godin JA, Millett PJ. Superior capsule reconstruction for massive rotator cuff tears-key considerations for rehabilitation. Int J Sports Phys Ther 2017;12:390-401.

12. Gagnier JJ, Kienle G, Altman DG, et al. The CARE guidelines: Consensus-based Clinical Case Reporting Guideline Development. Glob Adv Health Med 2013;2: 38-43.

13. Mihata T, Lee TQ, Watanabe $\mathrm{C}$, et al. Clinical results of arthroscopic superior capsule reconstruction for irreparable rotator cuff tears. Arthroscopy 2013;29:459-470.

14. Kim Y-S, Lee HJ, Park I, Sung GY, Kim DJ, Kim JH. Arthroscopic in situ superior capsular reconstruction using the long head of the biceps tendon. Arthrosc Tech 2018;7:e97-e103.

15. Laskovski JR, Boyd JA, Peterson EE, Abrams JS. Simplified technique for superior capsular reconstruction using an acellular dermal allograft. Arthrosc Tech 2018;7: el089-e1095.

16. Pennington WT, Chen SW, Bartz BA, Pauli JM. Arthroscopic superior capsular reconstruction with acellular dermal allograft using push-in anchors for glenoid fixation. Arthrosc Tech 2018;8:e51-e55.

17. Tokish JM, Momaya A, Roberson T. Superior capsular reconstruction with a partial rotator cuff repair: A case report. JBJS Case Connect 2018;8:e1.

18. Petri M, Greenspoon JA, Millett PJ. Arthroscopic superior capsule reconstruction for irreparable rotator cuff tears. Arthrosc Tech 2015;4:e751-e755.

19. van der Meijden OA, Westgard P, Chandler Z, Gaskill TR, Kokmeyer D, Millett PJ. Rehabilitation after arthroscopic rotator cuff repair: Current concepts review and evidence-based guidelines. Int $J$ Sports Phys Ther 2012;7:197-218.

20. Makovicka JL, Chung AS, Patel KA, Deckey DG, Hassebrock JD, Tokish JM. Superior capsule reconstruction for irreparable rotator cuff tears: A systematic review of biomechanical and clinical outcomes by graft type. J Shoulder Elbow Surg 2020;29:392-401.

21. Page P. Current concepts in muscle stretching for exercise and rehabilitation. Int J Sports Phys Ther 2012;7:109-119.

22. Brislin KJ, Field LD, Savoie FH III. Complications after arthroscopic rotator cuff repair. Arthroscopy 2007;23: 124-128.

23. Kluczynski MA, Nayyar S, Marzo JM, Bisson LJ. Early versus delayed passive range of motion after rotator cuff repair: A systematic review and meta-analysis. Am J Sports Med 2015;43:2057-2063.

24. Li S, Min S, Zhang H, Fu G, Wang P, Jin A. Effect of continuous passive motion on basic fibroblast growth factor expression during tendon-bone repair after surgical repair of acute rupture of the supraspinatus tendon in rabbits. Nan Fang Yi Ke Da Xue Xue Bao 2010;30: 1020-1023 [in Chinese].

25. Thomopoulos S, Williams GR, Soslowsky LJ. Tendon to bone healing: Differences in biomechanical, structural, and compositional properties due to a range of activity levels. J Biomech Eng 2003;125:106-113.

26. Greiner SH, Back DA, Herrmann S, Perka C, Asbach P. Degenerative changes of the deltoid muscle have impact on clinical outcome after reversed total shoulder arthroplasty. Arch Orthop Trauma Surg 2009;130:177.

27. Thigpen CA, Shaffer MA, Gaunt BW, Leggin BG, Williams GR, Wilcox RB 3rd. The American Society of Shoulder and Elbow Therapists' consensus statement on rehabilitation following arthroscopic rotator cuff repair. J Shoulder Elbow Surg 2016;25:521-535. 